\title{
ROTATIONAL STIFFNESS DETERMINATION OF THE SEMI-RIGID TIMBER-STEEL CONNECTION
}

\author{
Tomas GEČYS, Alfonsas DANIŪNAS \\ Department of Steel and Composite Structures, Faculty of Civil Engineering, \\ Vilnius Gediminas Technical Univesity, Sauletekio al. 11, LT-10223, Vilnius, Lithuania
}

Received 30 Jun 2017; accepted 13 Jul 2017

\begin{abstract}
In this research, the component method implementation for determination of the rotational stiffness of timber-steel connection is shown. Component method is one of the most commonly used methods for determination of the bending moment-rotation relation which later may be used in the practical analysis of the connection. The component method is not widely used for the analysis of the semi-rigid timber connections. There are only several investigations previously done on the component method implementation for the timber connections and most of them are based on only one basic component, i.e. timber compression or glued-in steel rod in tension. This article presents a new investigation of rotational stiffness determination algorithm of the semi-rigid timber-steel connection, which is based on the component method. The component method's mechanical model of the connection combines all components which have influence on the rotational stiffness of the connection. The analysed timber-steel connection is subjected to pure bending. Stiffness coefficients of the steel part components are determined according to the Eurocode 3: design of steel structures Part 1-8: Design of joints. The timber part components are derived from the full-scale laboratory experiments and finite element modelling results, presented in the previous publications of the authors. The presented rotational stiffness determination results are well in line with the experimental and finite element modelling results, published in the previous publications.
\end{abstract}

Keywords: timber-steel connection, rotational stiffness, semi-rigid connection.

\section{Introduction}

The evaluation of actual behaviour of the connection is significant important while the structure of connection mostly determines the cross-section dimensions of the whole element. Almost all connections in timber structures may be treated as semi-rigid with a certain rotational stiffness. Semi-rigid connections in timber structures are distinguished because of relatively low modulus of elasticity of timber, comparing with steel material and loose initial deformation modulus, if analysing traditional dowel-type timber connections. The rotational stiffness of the connection has high influence on the distribution of bending moments and displacements of the analysed frame. The concept of timber connection design is oriented to the plastic behaviour, rather than brittle, with an aim that plastic deformations would be reached before failure (Bruehl et al. 2011; Jorissen, Fragiacomo 2011; Malo et al. 2011; Malesza et al. 2017).

The behaviour of the semi-rigid connection is characterized by bending moment-rotation $M / \varphi$ curve. This relation may be determined by different methods: laboratory experiments; numerical modelling or mechanical methods, such as component method. The determination of connection's rotational stiffness based on full-scale experiments are performed for large screw-bolts (Komatsu et al. 2008, 2012); glued-in rods (Wakashima et al. 2010) and for dowel type fasteners (Awaludin, Smittakorn 2004; Awaludin et al. 2007). These methods are expensive and very time-consuming so mostly used for validation of the theoretical methods, such as component method.

Component method is one of the most commonly used methods for determination of the moment resistance and rotational stiffness of the connection. Component method enables determination of the moment resistance $M_{j, R d}$, and initial rotational stiffness $S_{j, \text { ini }}$. This method is widely implemented for H-type semi-rigid steel beam-tobeam, beam-to-column and column-to-foundation joints (Faella et al. 2000; Del Savio et al. 2009; Diaz et al. 2011; Kurejkova, Wald 2017). Component method is normally used for joints subjected to bending moment but there are some extensions of the component method which evaluate bending moment and axial force interaction (Urbonas, Daniūnas 2006; Daniūnas, Urbonas 2008). Component method combines all components affecting the moment resistance and rotational stiffness of the connection.

Corresponding author: Tomas Gečys

E-mail: tomas.gecys@vgtu.lt 
As it was mentioned before, component method is not widely used for calculations of semi-rigid timber connections. Although almost all timber connections should be treated as semi-rigid, European timber structures design code Eurocode 5 (EN 1995-1-1 2004) does not provide any methods for determination of the rotational stiffness of the connection. The previous investigations, done in the analysis of semi-rigid timber connections, mostly were focused on only one basic component in the connection: timber compression at various directions to the grain (Wald et al. 2000; Jirka, Mikes 2010; Descamps et al. 2006); glued-in rod tension (Xu et al. 2012) or dowel in bending (Awaludin, Smittakorn 2004). Also there are investigations done analysing complicated timber connections when several basic timber and steel components are combined using component method. Authors investigate timber-steel connections with glued-in steel rods and using component method theoretically determines the bending moment-rotation relation (Yang et al. 2016).

Further in this article the rotational stiffness determination is shown for the semi-rigid timber-steel connection using component method. The presented stiffness coefficient equations of each component are well in line with the laboratory experiment results and finite element modelling, presented in the previous publications of authors (Gečys, Daniūnas 2013; Gečys et al. 2015). The moment resistance of the analysed connection is assumed according to the previous publication (Daniūnas, Gečys 2015).

\section{Rotational stiffness determination using the component method}

The structure of analysed semi-rigid timber-steel connection with mechanical model, showing basic components, is shown in Figure 1. Semi-rigid timber-steel connection is composed of glued laminated timber elements (position 1 according to Fig. 1), T-shaped welded steel details (position 2 according to Fig. 1). The gap between welded steel detail and timber element is filled with cement based filler (position 5 according Fig. 1) in order to ensure the initial contact between glued laminated timber element and steel detail. The structure of the analysed connection is described in detail in the previous publications of authors (Gečys, Daniūnas 2013; Gečys et al. 2015). The basic components for the analysed connection are:

- end-plate in bending in the tension zone of the connection $\left(k_{e p b}\right)$;

- bolts in tension $\left(k_{b t}\right)$;

- steel plate in tension $\left(k_{s p t}\right)$;

- end-plate in bending caused by the tension, including timber compression in the tension zone of the connection $\left(k_{\text {ept }}\right)$;

- timber in tension $\left(k_{t t}\right)$;

- timber in shear, in the tension zone of the connection $\left(k_{t s}\right)$;

- steel plate in compression $\left(k_{s p c}\right)$;

- end-plate bending caused by the compression, including timber compression in the compressive zone of the connection $\left(k_{e p c}\right)$.
Two different types of components may be distinguished according to the behaviour: elastic-plastic which have influence on both, moment resistance and rotational stiffness and rigid, which do influence only moment resistance.

The rotational stiffness $S_{j}$ of the analysed connection is determined according to EN 1993-1-8 (2005):

$$
S_{j}=\frac{E \cdot z^{2}}{\mu \cdot \sum \frac{1}{k_{i}}} .
$$

The Eqn (1) may be transformed for the connection in which several different materials are interacting:

$$
S_{j}=\frac{z^{2}}{\mu \cdot \sum \frac{1}{E_{i} \cdot k_{i}}},
$$

where $k_{i}$ is the stiffness coefficient for basic joints component $i ; z$ is the lever arm; $\mu$ is the stiffness ratio $S_{j, \text { ini }} / S_{j} ; E_{i}$ is the modulus of elasticity of component $i$.

For the end-plate connections with two or more boltrows in tension, the basic components related to all of these bolt-rows should be represented by a single equivalent stiffness coefficient $k_{e q}$ determined by EN 1993-1-8 (2005):

$$
k_{e q}=\frac{\sum_{r} k_{e f f, r} \cdot h_{r}}{z_{e q}},
$$

where $h_{r}$ is the distance between bolt-row $r$ and the centre of compression; $k_{\text {eff, } r}$ is the effective stiffness coefficient for bolt-row $r ; z_{e q}$ is the equivalent lever arm, which is determined by:

$$
z_{e q}=\frac{\sum_{r} k_{e f f, r} \cdot h_{r}^{2}}{\sum_{r} k_{e f f, r} \cdot h_{r}} .
$$

The initial rotational stiffness $S_{j, \text { ini }}$ is determined using the Eqn (2) with ratio $\mu=1.0$. This ratio $\mu=\left(S_{j, \text { ini }}\right)^{\prime}$ $S_{j}$ ) for the semi-rigid steel joints is assumed equal to 1.0 when the bending moment $M_{j, E d} \leq 2 / 3 \cdot M_{j, R d}$; where $M_{j, R d}$ is the moment resistance of the joint. This equation shows that linear-elastic bending moment and rotation relation is assumed when the moment value is less than $2 / 3 M_{j, R d}$. When the bending moment value exceeds the value of $2 / 3 M_{j, R d}$, the stiffness ratio is determined by $\mu=\left(1.5 \cdot M_{j, E d} / M_{j, R d}\right)^{\psi}$, where $\psi$ is the coefficient with a value of 2.7-3.1, depending on the type of connection, according to EN 1993-1-8 (2005).

\section{Stiffness coefficients of basic components}

In this section the stiffness coefficient values of each basic component will be discussed. Steel part components mostly determined according to EN 1993-1-8 (2005) and 


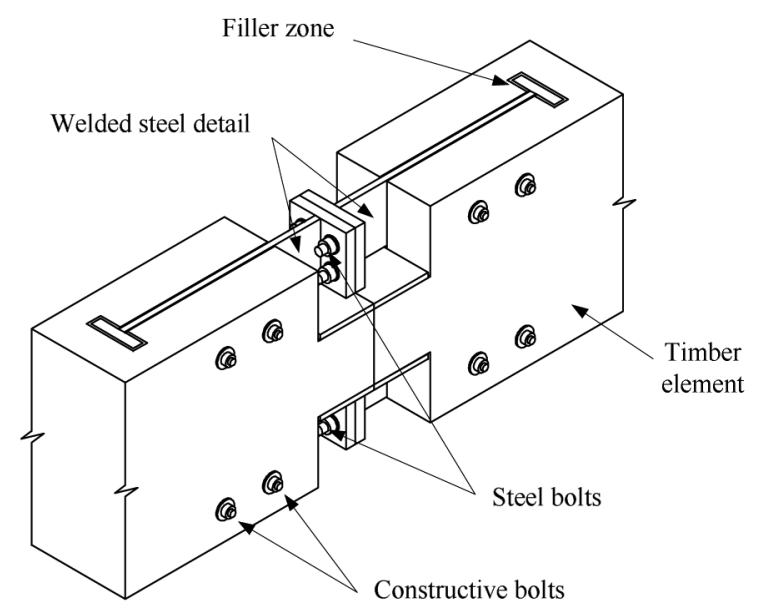

a)

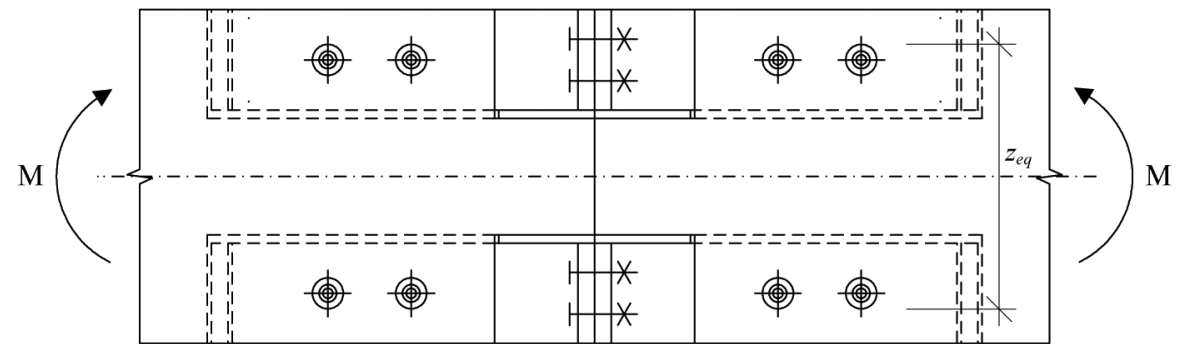

or Elastic-plastic component

b)

- - Rigid component

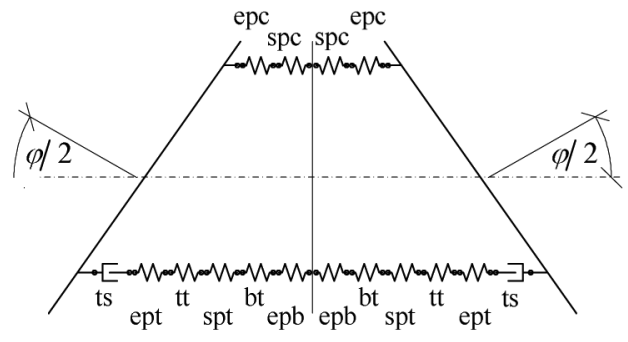

c)

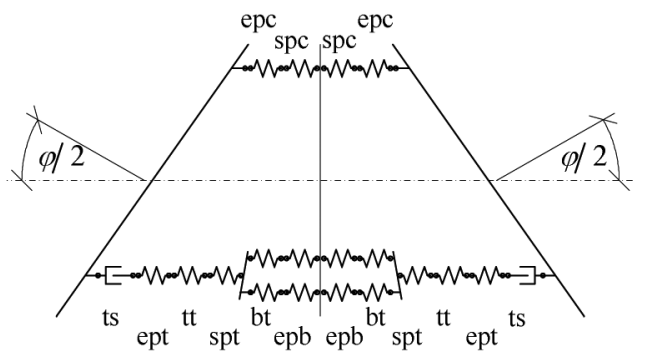

d)

Fig. 1. Mechanical model of the connection: a) 3D view of the connection; b) front view of the connection; c) model with one tension bolt-row; d) model with two tension bolt-rows

Faella et al. (2000). The timber part stiffness coefficient values are derived from the laboratory experiments and finite element modelling results presented in the previous publications (Gečys, Daniūnas 2013; Gečys et al. 2015).

\section{Stiffness coefficient $\mathrm{k}_{\mathrm{epb}}$}

The end-plate in bending, in the tension zone of the connection is analysed as separate T-stub element, assuming it as stiffened column flange. The implementation of the stiffened column flange for the end-plate bolted steel plate is shown in Figure 2.

The stiffness coefficient $k_{e p b}$ is determined according to EN 1993-1-8 (2005):

$$
k_{e p b}=\frac{0.9 \cdot l_{e f f} \cdot t_{p}^{3}}{m^{3}}
$$

where $l_{\text {eff }}$ is the smallest of effective lengths (individu- ally or as part of a bolt group) for analysed bolt-row; $t_{p}$ is the thickness of end-plate, as shown in Figure 2; $m$ is the distance as shown in Figure 2.

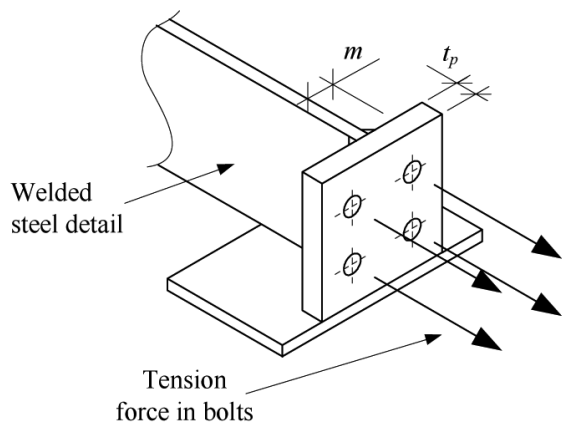

Fig. 2. Welded steel detail's parameters for bolted end-plate stiffness coefficient determination 


\section{Stiffness coefficient $\mathrm{k}_{\mathrm{bt}}$}

The stiffness coefficient of the steel bolts subjected to tension is determined according to EN 1993-1-8 (2005):

$$
k_{b t}=\frac{1.6 \cdot A_{s}}{L_{b}}
$$

where $A_{s}$ is the sum cross section of single bolt-row bolts; $L_{b}$ is the bolt elongation length.

Stiffness coefficients $\mathrm{k}_{\mathrm{spt}}$ and $\mathrm{k}_{\mathrm{spc}}$

The stiffness coefficient of the steel plate subjected to tension or compression is determined according to:

$$
k_{s p t(s p c)}=\frac{A_{p l}}{0.9 \cdot L_{p l}},
$$

where $A_{p l}$ is the cross section area of the longitudinal steel plate subjected to tension or compression; $L_{p l}$ is the length between end-plates.

The determination of the welded steel detail's longitudinal plate stiffness coefficient is based on the classical mechanics where the main issue is to determine the elongation length $L_{p l}$, as it is shown in Figure 3. The elongation of such longitudinal steel plate is determined according to the finite element modelling results. It was determined that the effective steel length where longitudinal deformations arise is equal to $0.9 L_{p l}$. This value reasonable represents the modelling results.

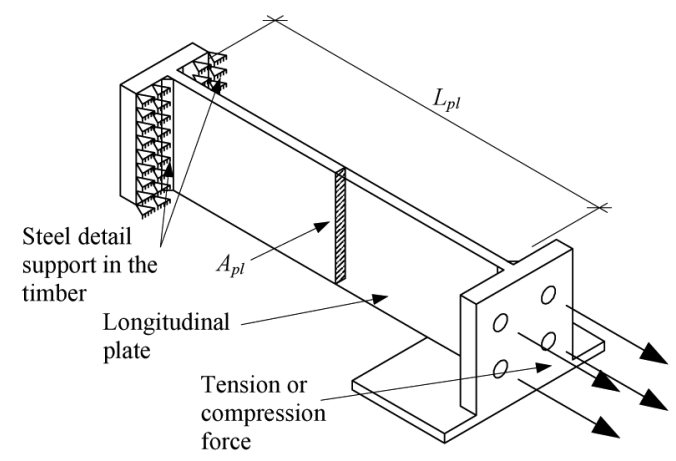

Fig. 3. Scheme for longitudinal steel plate stiffness coefficient determination

Stiffness coefficients $\mathrm{k}_{\mathrm{ept}}$ and $\mathrm{k}_{\mathrm{epc}}$

The stiffness coefficient of the steel plate subjected to tension or compression is determined according to the stiffness coefficient of the end-plate in bending, which is anchored into timber element, is calculated using the same methods which are developed for the concrete in compression, according to EN 1993-1-8 (2005). The equation is transformed by changing the modulus of elasticity of concrete with modulus of elasticity of timber $E_{T}$ :

$$
k_{\text {epc }(e p t)}=\frac{E_{T} \cdot \sqrt{b_{e f f} \cdot l_{\text {eff }}}}{1.275 \cdot E_{s}},
$$

where $E_{T}$ is the modulus of elasticity of timber; $E_{S}$ is the modulus of elasticity of steel; $b_{\text {eff }}$ and $l_{\text {eff }}$ are the effective

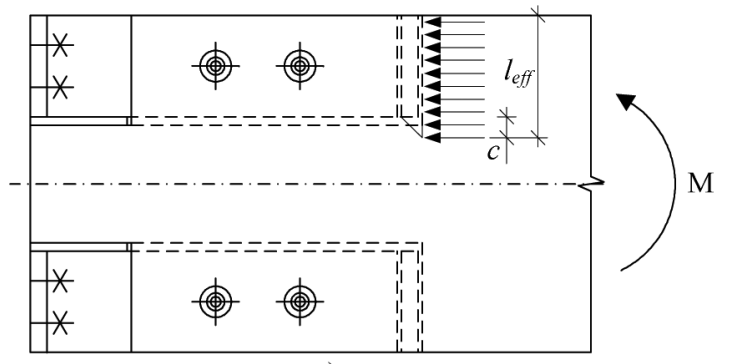

a)

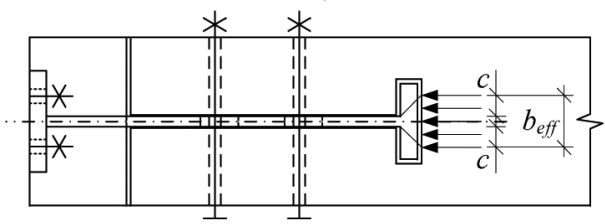

b)

Fig. 4. The effective compressive area of timber in the tight contact with steel detail: a) front view; b) the view from top

width and length of timber in compression, as shown in Figure 4.

The distance $c$, shown in Figure 4, is determined according to the equation provided in EN 1993-1-8 (2005), (Eqn 6.5) by replacing the strength of concrete with timber compressive strength $f_{c, 0, d}$.

Stiffness coefficient $\mathrm{k}_{\mathrm{tt}}$

Tension deformation distribution is shown in the Figure 5. Timber subjected to tension, stiffness coefficient is calculated according:

$$
k_{t t}=A_{t t} / 3\left(t_{g, p l}+2 t_{f i l}\right)
$$

where $A_{t t}$ is the timber cross section subjected to tension, $t_{g, p l}$ is the thickness of the end-plate, $t_{f i}$ is the thickness of filler material. In Figure 5 the effective length $l_{t t}$ is the total distance of timber elongation in the tight contact zone.

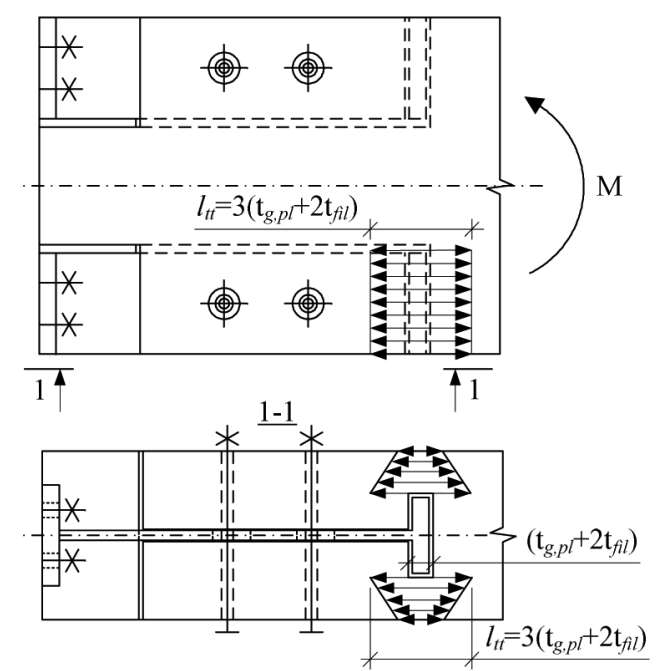

Fig. 5. Deformation distribution in timber, in the tension zone of the connection 


\section{Calculation results using component method and comparison with laboratory experiments and finite element modelling}

Calculations of the semi-rigid timber-steel connection rotational stiffness are presented using the above developed component method. Dimensions of the analysed connection are shown in Figure 6 which fully correspond with the connection previously investigated experimentally (Gečys, Daniūnas 2013) and by finite element modelling (Gečys et al. 2015). The theoretical moment resistance of the connection is $M_{j, R, \text { comp }}=54.5 \mathrm{kNm}$, according to the publication (Daniūnas, Gečys 2015). The theoretically determined initial rotational stiffness of the connection, provided in Figure 6 (Joint 1), is $S_{\text {j,ini,comp }}=7120 \mathrm{kNm} / \mathrm{rad}$. Also, 6 Joints are investigated using component method, changing the end-plate thickness from basic value $20 \mathrm{~mm}$ to $10 \mathrm{~mm}$, as it is shown in Figure 6 .

The component method used for calculation of the connection is explained in detail in Chapter 2. The initial stiffness values of each basic component of the connection are graphically depicted in Figure 7. While the

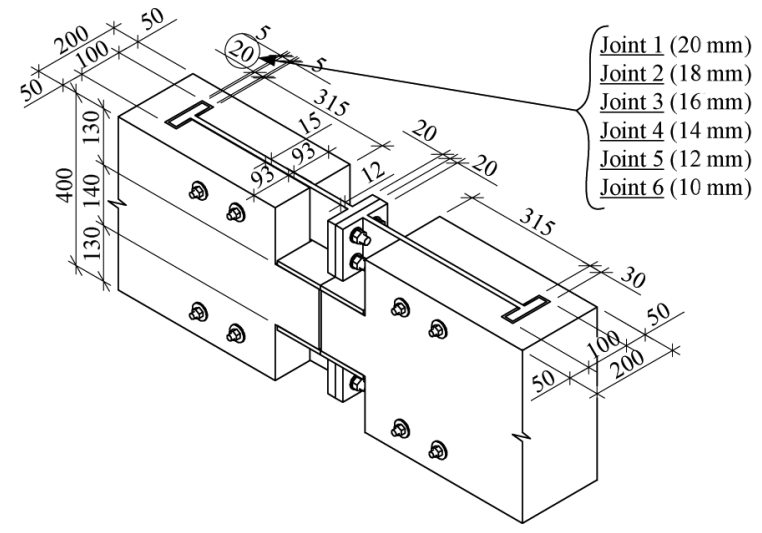

Fig. 6. Dimensions of the connection analysed timber-steel connection consists of timber and steel components, values of each component stiffness coefficient are multiplied with modulus of elasticity of each component, provided in Figure 7.

After determination of the initial rotational stiffness $S_{j, \text { ini,comp }}$, the rotational stiffness of the connection $S_{j, \text { comp }}$ should be determined which represent the moment-rotation relation up to the design moment resistance $M_{j, R d}$. Figure 8 shows different moment-rotation curves, representing different elastic ranges of the moment resistance (2/3 $M_{j, R d}$ and $\left.2 / 5 M_{j, R d}\right)$ and different values of coefficient $\psi$. The curve A shows the moment-rotation curve based on the method provided for semi-rigid steel joints. Analysing semi-rigid beam-to-beam or beam-to-column steel joints, the initial rotational stiffness is assumed when $M_{j, E d} \leq 2 / 3 \cdot M_{j, R d}$. After the bending moment value exceeds the value of $2 / 3 M_{j, R d}$, the stiffness ratio is determined as $\mu=\left(1.5 \cdot M_{j, E d} / M_{j, R d}\right)^{\psi}$. This curve does not represent precisely the corresponding laboratory experiments (CEM-2, CEM-3, and CEM-4) which are presented in the previous publication (Daniūnas, Gečys

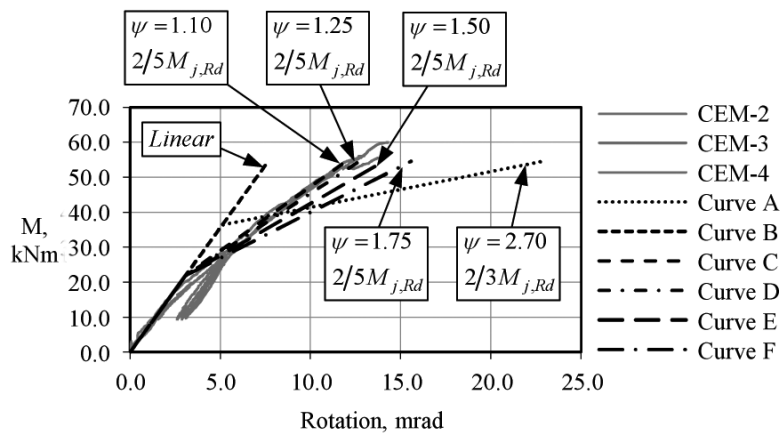

Fig. 8. Different moment-rotation curves: laboratory experiments (CEM-2, CEM-3, CEM-4) and component method calculations (curves A, B, C, D, E, F)

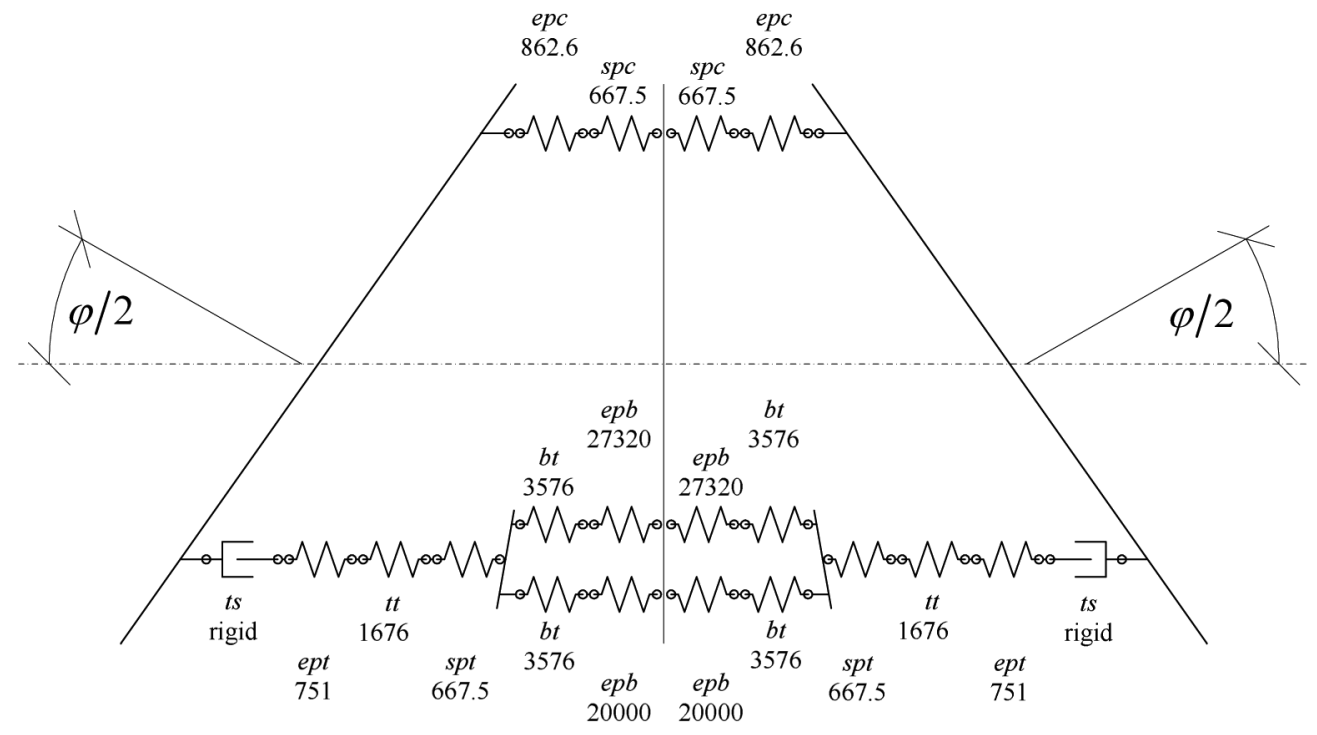

Fig. 7. Graphic depiction of basic component values (values are in $\mathrm{kN} / \mathrm{mm}$ ) 


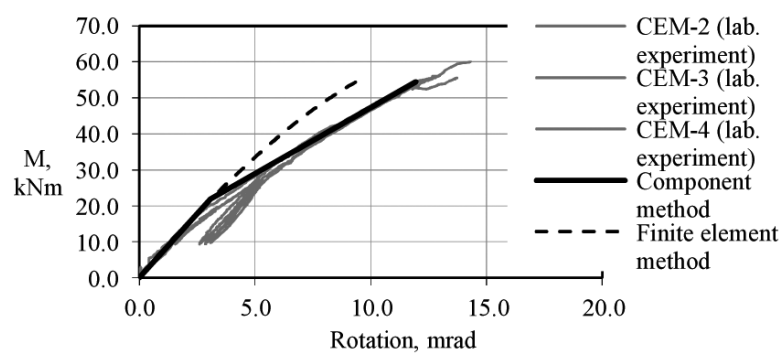

Fig. 9. Comparison between different moment-rotation curves: component method based theoretical, experimental and finite element modelling

2015). The curve $B$ represent the linear moment-rotation relation up to the $M_{j, R d}$. Curves C, D, E, F are determined assuming the linear moment-rotation relation up to $2 / 5$ $M_{j, R d}$ and the joint type coefficient $\psi$ equal to $1.1 ; 1.25$; $1.5 ; 1.75$, respectively. Analysis of different moment-rotation curves shows that behaviour of the connection is the most precisely represented by the curve $\mathrm{C}$ (elastic range up to $2 / 5 M_{j, R d}$ and joint type coefficient $\psi=1.1$ ).

Assuming the moment-rotation curve $\mathrm{C}$ (which represent the elastic range up to $2 / 5 M_{j, R d}$ and joint type coefficient $\psi=1.1$ ), the comparison between theoretical, laboratory experiments (Gečys, Daniūnas 2013) and finite element modelling (Gečys et al. 2015) results with reference to the moment-rotation curve, are shown in Figure 9.

The developed rotational stiffness determination algorithm is implemented for the calculations of the analysed connection. The aim of these calculations is to show the rotational stiffness change while changing the embedded T-shaped end-plate thickness. 6 different end-plate thicknesses were taken for the calculation. Figure 10 shows the moment resistance and rotational stiffness change, while changing the end-plate thickness. Also, the failure mode is different at different thickness of plate. While changing the end-plate thickness from $20 \mathrm{~mm}$ to $14 \mathrm{~mm}$, the moment resistance does not change while the determining parameter in bending capacity calculation is timber shear which has no relation with endplate thickness. The rotational stiffness decrease by $7.8 \%$ when the end-plate thickness is changed from $20 \mathrm{~mm}$ to $14 \mathrm{~mm}$. Taking the end-plate thickness equal to $12 \mathrm{~mm}$ and less, the failure mode changes from timber shear, to the failure caused by timber compression and steel yield in the tight contact zone between timber and steel. The initial rotational stiffness $S_{j, \text { ini,comp }}$ decreases by $12.2 \%$ comparing connections with $20 \mathrm{~mm}$ and $12 \mathrm{~mm}$ end-plate thicknesses.

The initial rotational stiffness of the analysed connection consists of several basic components, previously discussed. Figure 10 shows the influence of each component on the initial rotational stiffness at the level of loading up to $40 \%$ from maximum load, which is in the elastic range. It is obvious that for joints with relatively thick end-plate, the greatest influence on the rotational

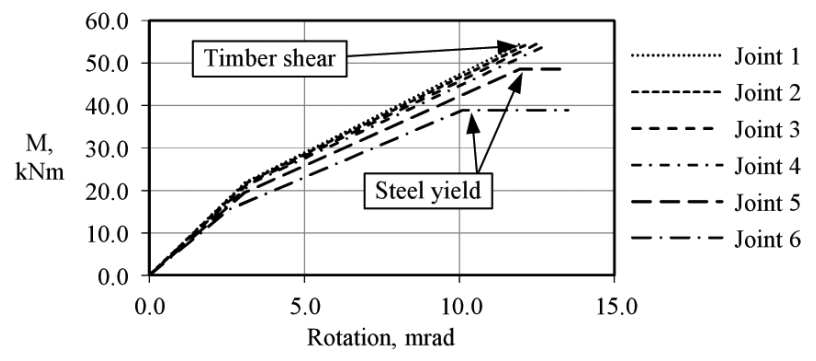

Fig. 10. Component method based moment-rotation curves for joints with different end-plate thicknesses

stiffness is because of the steel plate tension $\left(k_{s p t}\right)$ and compression $\left(k_{s p c}\right)$. Decreasing the end-plate thickness, the determining parameter is end-plate bending caused by the compression $\left(k_{e p c}\right)$ or tension $\left(k_{e p t}\right)$, including timber compressive or tension zone of the connection.

Figure 11 clearly shows that changing the end-plate thickness there is possibility to reach the corresponding rotational stiffness value of the connection. The corresponding rotational stiffness of the connection is necessary for the optimal design of the timber frame elements.

\section{Conclusions}

This paper presents a new investigation based on extension of component method used for semi-rigid steel joints. The extension of the component method is used for determination of initial rotational stiffness of the semi-rigid timber-steel connection which is combined of both, timber and steel components. The novelty of the research is summarized in conclusions providing the proposed joint type coefficient value and newly proposed stiffness coefficient expressions. Further main conclusions may be depicted:

1. The extended component method, used for the analysis of semi-rigid steel connections, may be used for the determination of rotational stiffness of the analysed timber-steel connection. The theoretically determined initial rotational stiffness of the connection is $20.3 \%$ higher than the experimental results. To reach better compliance between theoretical and experimental results, the further investigation may be done focusing on the stiffness coefficient of timber shear, while this component was assumed as rigid.

2. The comparison between experimental, finite element modelling and theoretical calculation results shows that the elastic range of the connection is up to the value $2 / 5 M_{j, R d}$. The proposed value of the joint coefficient $\psi=1.1$ reasonably represent the behaviour of the connection in the elastic-plastic range, when the bending moment value is above $2 / 5 M_{j, R d}$.

3. The steel plate subjected to tension or compression $\left(k_{s p t}\right.$ and $\left.k_{s p c}\right)$ are adjusted using classic mechanics theory clarifying the effective length for elongation or shortening. The stiffness coefficient of end-plate bending $\left(k_{e p t}\right.$ and $\left.k_{e p c}\right)$, caused by tension, is determined by implementing the equation which is pro- 

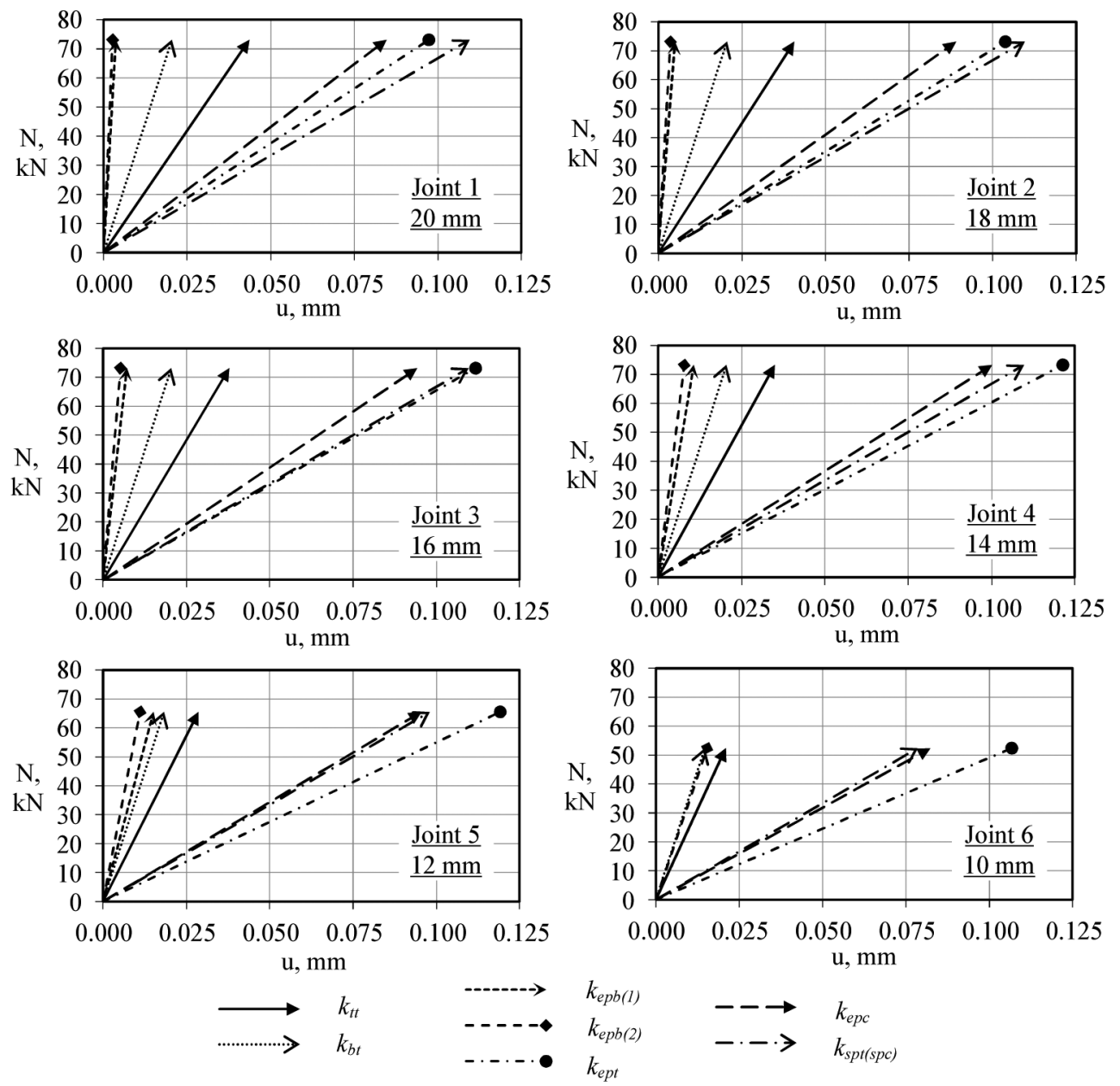

Fig. 11. Load-deformation curves of components for joints 1, 2, 3, 4, 5 and 6

vided for the T-shaped equivalent element in steel joints. The new equation for determination of stiffness coefficient of timber subjected to tension $\left(k_{t t}\right)$ is provided.

4. Component method rotational stiffness calculation results performed using different end-plate thicknesses, show that the most decisive components for the rotational stiffness are steel plate tension $\left(k_{s p t}\right)$ or compression $\left(k_{s p c}\right)$. For connections with relatively small end-plate thickness, the greatest impact is caused by the end-plate bending, conditioned by the compression $\left(k_{\text {epc }}\right)$ or tension $\left(k_{\text {ept }}\right)$, including timber compressive or tension zone deformations of the connection.

\section{References}

Awaludin, A.; Smittakorn, W. 2004. Flexural resistance of steel to wood connection with various multiple-bolt configurations, in The $17^{\text {th }}$ KKCNN Symposium on Civil Engineering, 2004, Ayutthaya, Thailand, 321-326.

Awaludin, A.; Smittakorn, W.; Hayashikawa, T.; Hirai, T. 2007. M-theta curve of timber connection with various bolt arrangements under monotonic loading, Journal of Structural Engineering 53: 853-862.
Bruehl, F.; Kuhlmann, U.; Jorissen, A. 2011. Consideration of plasticity within the design of timber structures due to connection ductility, Engineering Structures 33: 30073017. https://doi.org/10.1016/j.engstruct.2011.08.013

Daniūnas, A.; Gečys, T. 2015. Component method implementation for calculations of timber-steel connection, Gradevinar 11: 105-112.

Daniūnas, A.; Urbonas, K. 2008. Analysis of the steel frames with semi-rigid beam-to-beam and beam-to-column knee joints under bending and axial forces, Engineering Structures 30: 3114-3118.

https://doi.org/10.1016/j.engstruct.2008.04.027

Del Savio, A. A.; Nethercot, D. A.; Vellasco, P. C. G. S.; Andrade, S. A. L.; Martha, L. F. 2009. Generalised component-based model for beam-to-column connections including axial versus moment interaction, Journal of Constructional Steel Research 65: 1876-1895. https://doi.org/10.1016/j.jcsr.2009.02.011

Descamps, T.; Lambion, J.; Laplume, D. 2006. Timber structures: rotational stiffness of carpentry joints, in Proceedings of the $9^{\text {th }}$ World Conference on Timber Engineering, 2006, Portland Oregon State University, Portland.

Diaz, C.; Marti, P.; Victoria, M.; Querin, O. M. 2011. Review on the modelling of joint behaviour in steel frames, Journal of Constructional Steel Research 67: 741-758. https://doi.org/10.1016/j.jcsr.2010.12.014

EN 1993-1-8 Eurocode 3: Design of steel structures-Part 1-8: Design of joints. European Committee for Standardisation, 2005. 
EN 1995-1-1 Eurocode 5: Design of timber structures-Part 1-1: General-Common rules and rules for building. European Committee for Standardisation, 2004.

Faella, C.; Piluso, V.; Rizzano, G. 2000. Structural steel semirigid connections. Theory, Design and Software. CRC Press LLC, N. W. Corporate Blvd., Boca Raton, Florida.

Gečys, T.; Daniūnas, A. 2013. Experimental investigation of glued laminated timber beam to beam connections filled with cement based filler, Procedia Engineering 57: 320326. https://doi.org/10.1016/j.proeng.2013.04.043

Gečys, T.; Daniūnas, A.; Bader, T. K.; Wagner, L.; Eberhardsteiner, J. 2015. 3D finite element analysis and experimental investigations of a new type of timber beam-to-beam connection, Engineering Structures 86: 134-145. https://doi.org/10.1016/j.engstruct.2014.12.037

Jirka, O.; Mikes, K. 2010. Semi-rigid joints of timber structures, International Journal for Engineering and Information Sciences 5(2): 19-26. https://doi.org/10.1556/Pollack.5.2010.2.2

Jorissen, A.; Fragiacomo, M. 2011. General notes on ductility in timber structures, Engineering Structures 33: 2987-2997. https://doi.org/10.1016/j.engstruct.2011.07.024

Komatsu, K.; Akagi, M.; Kawai, Ch. et al. 2008. Improved column-beam joint in glulam semi-rigid portal frame, in Proceedings of the $10^{\text {th }}$ World Conference on Timber Engineering, 2008, Miyazaki, Japan.

Komatsu, K.; Nakashima, Sh.; Kitamori, A. 2012. Development of ductile moment-resisting joint based on a new idea for glulam portal frame structures, in Proceedings of the $12^{\text {th }}$ World Conference on Timber Engineering, 2012, Auckland, New Zealand.

Kurejkova, M.; Wald, F. 2017. Design of haunches in structural steel joints, Journal of Civil Engineering and Management 23(6): 765-772. https://doi.org/10.3846/13923730.2017.1281838
Malesza, J.; Miedzialowski, C.; Ustinovichius, L. 2017. Tests on full-scale and static analysis models of the wood-framed building structure horizontaly loaded, Journal of Civil Engineering and Management 23(6): 814-823. https://doi.org/10.3846/13923730.2017.1319411

Malo, K. A.; Siem, J.; Ellingsbo, P. 2011. Quantifying ductility in timber structures, Engineering Structures 33: 29983006. https://doi.org/10.1016/j.engstruct.2011.03.002

Urbonas, K.; Daniūnas, A. 2006. Behaviour of semi-rigid steelbeam-to-beam joints under bending and axial forces, Journal of Constructional Steel Research 12: 1244-1249. https://doi.org/10.1016/j.jcsr.2006.04.024

Wakashima, Y.; Okura, K.; Kyotani, K. 2010. Development of ductile semi-rigid joints with lagscrewbolts and gluedin rods, in Proceedings of the $11^{\text {th }}$ World Conference on Timber Engineering, 2010, Trentino, Italy.

Wald, F.; Mareš, J.; Sokol, Z.; Drdácký, M. 2000. Component method for historical timber joints, in C. C. Banitopoulos, F. Wald (Eds.). The paramount role of joints into the reliable response of structures, NATO Science Series, Series II, Vol. 4. Dortrecht: Kluver Academic Publishers, 417-424.

Xu, B. H.; Bouchair, A.; Racher, P. 2012. Analytical study and finite element modelling of timber connections with gluedin rods in bending, Construction and Building Materials 34: 337-345. https://doi.org/10.1016/j.conbuildmat.2012.02.087

Yang, H.; Liu, W.; Ren, X. 2016. A component method for moment-resistant glulam beam-column connections with glued-in steel rods, Engineering Structures 115: 42-54. https://doi.org/10.1016/j.engstruct.2016.02.024

Tomas GEČYS. Dr, Assoc. Prof. at the Department of Steel and Composite Structures of Vilnius Gediminas Technical University. Research interests: steel and timber structures, modelling of semi-rigid timber-steel connections, theoretical moment-rotation relation of timber and steel connections.

Alfonsas DANIŪNAS. Dr, Assoc. Prof. at the Department of Steel and Composite Structures of Vilnius Gediminas Technical University. He is an author and co-author of over 150 articles in science and organization of higher education. Research interests: steel and timber structures, analysis and optimization of elastic and plastic steel structures, numerical methods, semi-rigid joints of steel structures. 